\title{
Reproductive performance of grazing dairy cows following presynchronization and resynchronization protocols
}

\author{
E. S. Ribeiro, R. L. A. Cerri, ${ }^{1}$ R. S. Bisinotto, F. S. Lima, F. T. Silvestre, ${ }^{2}$ L. F. Greco, W. W. Thatcher, \\ and J. E. P. Santos ${ }^{3}$ \\ Department of Animal Sciences, University of Florida, Gainesville 32611
}

\begin{abstract}
Objectives were to compare the effect of presynchronization and resynchronization methods on fertility responses of grazing dairy cows at first and second artificial insemination (AI) and pregnancy rate during the entire breeding season. Lactating dairy cows $(\mathrm{n}=$ $1,263)$ in 2 seasonal grazing farms were blocked, within farm, by parity, breed and days in milk. Within each block, cows were randomly assigned to 1 of 4 treatments arranged as a $2 \times 2$ factorial with 2 presynchronization and 2 resynchronization treatments. Cows had their estrous cycles presynchronized with either a $\mathrm{PGF}_{2 \alpha}$-based program (Presynch) consisting of 2 injections of $\mathrm{PGF}_{2 \alpha}$ administered $14 \mathrm{~d}$ apart and starting the timed AI protocol $11 \mathrm{~d}$ later, or with a $\mathrm{PGF}_{2 \alpha}-\mathrm{GnRH}$-based presynchronization program (G6G) consisting of an injection of $\mathrm{PGF}_{2 \alpha}$, followed $3 \mathrm{~d}$ later by an injection of $\mathrm{GnRH}$ and starting the timed AI protocol $6 \mathrm{~d}$ later. All cows received the first insemination on the same day, which was considered study d 0 and also d 0 of the breeding season. All cows received the 5-d timed AI protocol that consisted of $\mathrm{GnRH}$ on $\mathrm{d}-8, \mathrm{PGF}_{2 \alpha}$ on $\mathrm{d}-3$ and -2 , and GnRH + timed AI on d 0. Blood was sampled and analyzed for progesterone on $\mathrm{d}-8$. On $\mathrm{d} 12$, cows in each presynchronization treatment either remained as untreated controls (RCON) or received a controlled internal drug-release (CIDR) insert containing progesterone for $7 \mathrm{~d}$ (RCIDR). Estrus was observed daily starting on d 19 and cows in estrus were inseminated on the same day. On d 35, bulls were placed with the cows for an additional $65 \mathrm{~d}$, completing a 100-d breeding season. Holstein cows were less likely to have progesterone $\geq 1 \mathrm{ng} / \mathrm{mL}$ on $\mathrm{d}-8$, and had less expression of estrus and pregnancy per $\mathrm{AI}(\mathrm{P} / \mathrm{AI})$, which resulted in a slower rate of pregnancy and a smaller proportion of pregnancy at the end of the study than did Jersey or
\end{abstract}

\footnotetext{
Received January 31, 2011.

Accepted May 18, 2011.

${ }^{1}$ Current address: University of British Columbia, Vancouver, BC

${ }^{2}$ Current address: Pfizer Animal Health, Bakersfield, CA 93101.

${ }^{3}$ Corresponding author: Jepsantos@ufl.edu
} V6T 1 Z4. crossbred cows. In addition, body condition, days in milk, and plasma progesterone concentration at the first GnRH injection of the timed AI protocol had marked effects on the reproductive performance of lactating grazing dairy cows. A greater proportion of G6G cows had progesterone $\geq 1 \mathrm{ng} / \mathrm{mL}$ at the first $\mathrm{GnRH}$ injection of the timed AI protocol compared with Presynch cows (82.0 vs. $74.3 \%$ ). Presynchronization treatment did not influence P/AI, but cows in G6G had increased risk of pregnancy loss between d 30 and 65 after the first AI (12.9 vs. 8.1\%). Nevertheless, an interaction between presynchronization and ovarian status was observed, and cows initiating the timed AI with progesterone $\geq 1$ $\mathrm{ng} / \mathrm{mL}$ had greater P/AI when previously treated with Presynch than G6G. On the other hand, G6G benefited $\mathrm{P} / \mathrm{AI}$ of cows initiating the timed AI with progesterone $<1 \mathrm{ng} / \mathrm{mL}$. Resynchronization with RCIDR altered the pattern of return to estrus, but it did not increase the rate of re-insemination and decreased the proportion of pregnant cows at the end of the 100-d breeding period ( 80.6 vs. $84.4 \%$ ).

Key words: breeding season, grazing cow, presynchronization, resynchronization

\section{INTRODUCTION}

Seasonal breeding is a strategy often used in pasturebased systems to simplify management and to match calving and breeding periods to better climatic conditions and forage quality/availability. Cows must become pregnant in a short and pre-established period of time to maximize productive efficiency and decrease the risk of culling. High submission early in the breeding period is also important to maintain the required concentrated calving pattern (Rhodes et al., 2003), which is economically important (McDougall, 2010). Synchronization protocols for timed AI allow for all cows to be inseminated in the first day of the breeding season, increasing the proportion of cows pregnant early in the breeding period. They constitute an effective treatment for anovular cows, which is a major problem in seasonal grazing farms, and also represent a profitable strategy when managing cows not expressing estrus before the 
anticipated mating period (McDougall, 2010). Collectively, these facts justify the use of timed AI programs for reproductive management in grazing dairy herds using seasonal breeding.

In programs based solely on $\mathrm{PGF}_{2 \alpha}$ and $\mathrm{GnRH}$, synchronization of the follicular wave and pregnancy per AI (P/AI) are optimized when cows ovulate to the first $\mathrm{GnRH}$ injection of the timed AI protocol (Vasconcelos et al., 1999; Chebel et al., 2006). Cows that initiate the timed AI protocol in early diestrus have decreased occurrence of spontaneous luteolysis and a greater probability to bear a dominant follicle that ovulates in response to a $\mathrm{GnRH}$ injection (Vasconcelos et al., 1999). Furthermore, inducing ovulation during early diestrus with the first GnRH limits the period of follicle dominance (Cerri et al., 2009), and ensures that the ovulatory follicle develops under high systemic concentrations of progesterone, both of which have been shown to benefit fertility (Bisinotto et al., 2010; Santos et al., 2010).

A program commonly used to improve responses to timed AI protocols is to administer 2 injections of $\mathrm{PGF}_{2 \alpha} 14 \mathrm{~d}$ apart, with the second injection 10 to 12 d before the first GnRH of the timed AI protocol to presynchronize the estrous cycle (Moreira et al., 2001; Galvão et al., 2007a). In addition to manipulating estrous cycle patterns, it might also benefit uterine health by inducing estrus in cyclic cows. Nevertheless, it has restricted effects in anovular cows [as defined by those without corpus luteum (CL) but with follicle development beyond the expected deviation diameter], which limits the efficiency of presynchronization. In contrast, GnRH induces ovulation in $76 \%$ of the cows without a CL (Galvão et al., 2007a) and 88\% in anovular cows (Gümen et al., 2003). Therefore, combining GnRH and $\mathrm{PGF}_{2 \alpha}$ for presynchronization might benefit anovular cows by inducing estrous cyclicity before the initiation of the timed AI program. Bello et al. (2006) demonstrated that administering $\mathrm{PGF}_{2 \alpha}$, followed $2 \mathrm{~d}$ later by GnRH, improved ovulatory response to the first GnRH of the timed AI protocol when it was initiated $6 \mathrm{~d}$ after presynchronization. In that study, $81 \%$ of the cows initiated a synchronized estrous cycle after the presynchronization treatment, and $92 \%$ ovulated synchronously after the timed AI protocol. Incorporating the GnRH in the presynchronization might benefit anovular cows, whereas $2 \mathrm{PGF}_{2 \alpha}$ injections might better presynchronize the cycle of cyclic cows; therefore, a tradeoff between the 2 strategies might exist.

Cows that fail to conceive at the first AI must be reinseminated shortly after the previous service to ensure adequate reproductive performance in seasonal breeding programs. In herds that opt for additional
AI, improving estrous detection and reinsemination of nonpregnant cows after the first $\mathrm{AI}$ is expected to enhance reproductive performance. Intravaginal inserts containing progesterone have been used to synchronize return to estrus in nonpregnant cows (Chenault et al., 2003; El-Zarkouny and Stevenson, 2004; Galvão et al., 2007b). Early resynchronization using progesterone inserts concentrates AI on fewer days, which might simplify labor and benefit embryo survival to the pretreatment AI (El-Zarkouny and Stevenson, 2004; Chebel et al., 2006).

The first hypothesis was that presynchronization with $\mathrm{PGF}_{2 \alpha} / \mathrm{GnRH}$ compared with $\mathrm{PGF}_{2 \alpha}$ alone would improve the proportion of cows initiating the timed AI protocol in diestrus and enhance P/AI. The second hypothesis was that incorporation of an intravaginal progesterone insert in an early resynchronization strategy would increase reinsemination of nonpregnant cows and improve pregnancy rate. Combining these effects was expected to improve reproduction during the breeding season. Therefore, the objectives were to compare the effect of presynchronization and resynchronization methods on fertility responses of grazing dairy cows during the breeding season.

\section{MATERIALS AND METHODS}

\section{Cows, Pasture, and Management}

The study was conducted on 2 commercial grazing dairy farms located in Trenton, FL. Both were fallcalving herds and used similar genetics and management practices. The average milk production per cow was approximately $6,000 \mathrm{~kg} /$ lactation. A total of 1,263 lactating dairy cows (457 Holsteins, 185 Jerseys, and 621 Holstein/Jersey crossbreds) were enrolled in this study. The population of crossbred cows was primarily composed of F1 (50/50) and F2 (25/75) generations of Holstein/Jersey genetics. Different genetic groups were managed together in a pasture-based system in both herds. Cows were maintained under irrigated pasture paddocks of 2.7 ha and managed in a daily rotational system with a stocking rate of approximately 10 cows/ ha. The pasture was composed of annual ryegrass ( $\mathrm{Lo}-$ lium multiflorum Lam.) during winter and early spring, and Tifton 85 Bermudagrass (Cynodon spp.) during late spring and summer. Cows were offered variable amounts of a concentrate mixture ( 7 to $13 \mathrm{~kg} /$ cow per day) during and immediately after each milking, according to forage availability and stage of lactation. The concentrate was based on soybean hulls, citrus pulp, whole cottonseed, cottonseed hulls, corn gluten feed, corn meal, soybean meal, molasses, and a mineral- 
vitamin premix, and designed to contain approximately $15 \% \mathrm{CP}, 4.5 \%$ fat, and $28 \% \mathrm{NDF}$. Cows were milked twice daily.

\section{Reproductive Management}

Cows were subjected to 100-d breeding seasons, from December 2008 to March 2009 in dairy A, and from January to April 2009 in dairy B. Presynchronization treatments were scheduled such that all cows, within farm, received timed AI on the same day, which was considered d 0 of the breeding season and $\mathrm{d} 0$ of the study. Nonpregnant cows after the first AI had an additional opportunity to be inseminated on detection of estrus between d 19 and 35. On d 36, bulls were placed with the cows for an additional $65 \mathrm{~d}$ of natural service.

\section{Experimental Design and Randomization}

Within herd, cows were blocked by parity (primiparous and multiparous), breed group, and DIM. Within each block, cows were randomly assigned to 1 of 4 treatments arranged as a $2 \times 2$ factorial with 2 presynchronization (Figure 1) and 2 resynchronization treatments (Figure 2).

\section{Presynchronization Treatments and Timed Al Protocol}

The presynchronization treatments were either a $\mathrm{PGF}_{2 \alpha}$-based program (Presynch), consisting of 2 in- jections of $\mathrm{PGF}_{2 \alpha}$ (Lutalyse sterile solution; $5 \mathrm{mg} / \mathrm{mL}$ of dinoprost tromethamine; Pfizer Animal Health Inc., Madison, NJ) administered $14 \mathrm{~d}$ apart and starting the timed AI protocol $11 \mathrm{~d}$ later after the second $\mathrm{PGF}_{2 \alpha}$; or a $\mathrm{PGF}_{2 \alpha}-\mathrm{GnRH}$-based presynchronization program (G6G), consisting of an injection of $\mathrm{PGF}_{2 \alpha}$, followed $3 \mathrm{~d}$ later by an injection of GnRH (Cystorelin; $50 \mu \mathrm{g}$ / $\mathrm{mL}$ of gonadorelin diacetate tetrahydrate; Merial Ltd., Iselin, NJ) and starting the timed AI protocol $6 \mathrm{~d}$ later. All cows were subjected to the 5-d timed AI protocol (Figure 1; Santos et al., 2010), and they were inseminated on $\mathrm{d} 0$ regardless of detection of estrus. On $\mathrm{d}-3$, cows had their tailheads painted using an oil-based tail paint (Donaghy tail paint; Donaghy's Industries Ltd., Dunedin, NZ) for detection of estrus on the day of AI, based on removal of tail paint. The first postpartum insemination was performed by the same 9 technicians on both farms. Seven Jersey ( $\mathrm{n}=728 \mathrm{AI}), 4$ Holstein (n $=398 \mathrm{AI})$, and 2 Swedish Red $(\mathrm{n}=137 \mathrm{AI})$ sires were used and sires and technicians were balanced across all 4 treatments.

\section{Resynchronization Treatments and Natural Service}

On d 12, all cows in each presynchronization treatment were submitted to 1 of the 2 resynchronization treatments (Figure 2) according to the initial randomization. Cows in the control resynchronization $(\mathbf{R C O N})$ did not receive any further treatment, whereas cows resynchronized with a controlled internal drug release containing progesterone (Eazi-Breed CIDR

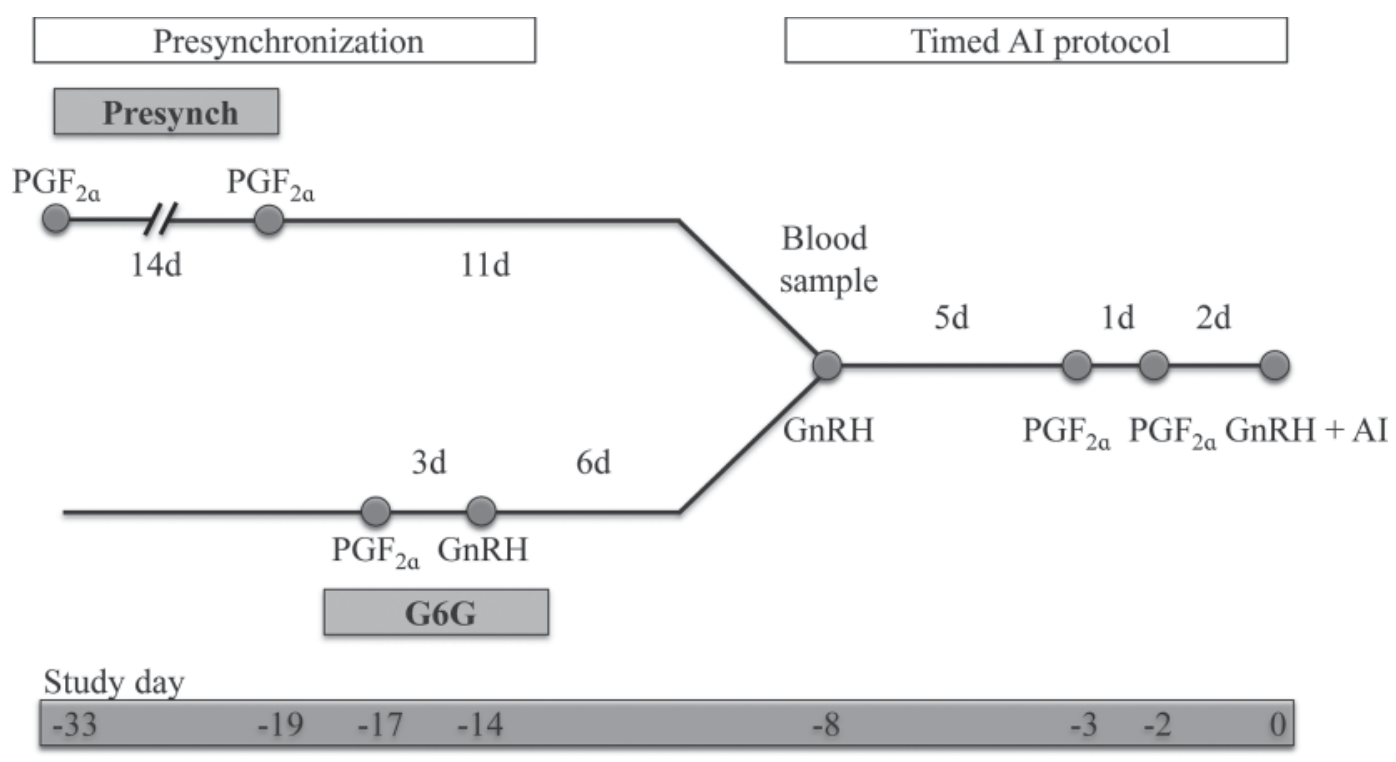

Figure 1. Diagram of activities for the presynchronization treatments and timed AI program. Presynch $=2$ injections of $\mathrm{PGF} \mathrm{F}_{2 \alpha}$, given 14 $\mathrm{d}$ apart and starting the timed AI protocol $11 \mathrm{~d}$ later. G6G = injection of $\mathrm{PGF}_{2 \alpha}$, followed $3 \mathrm{~d}$ later by an injection of GnRH and starting the timed AI protocol 6 d later. 


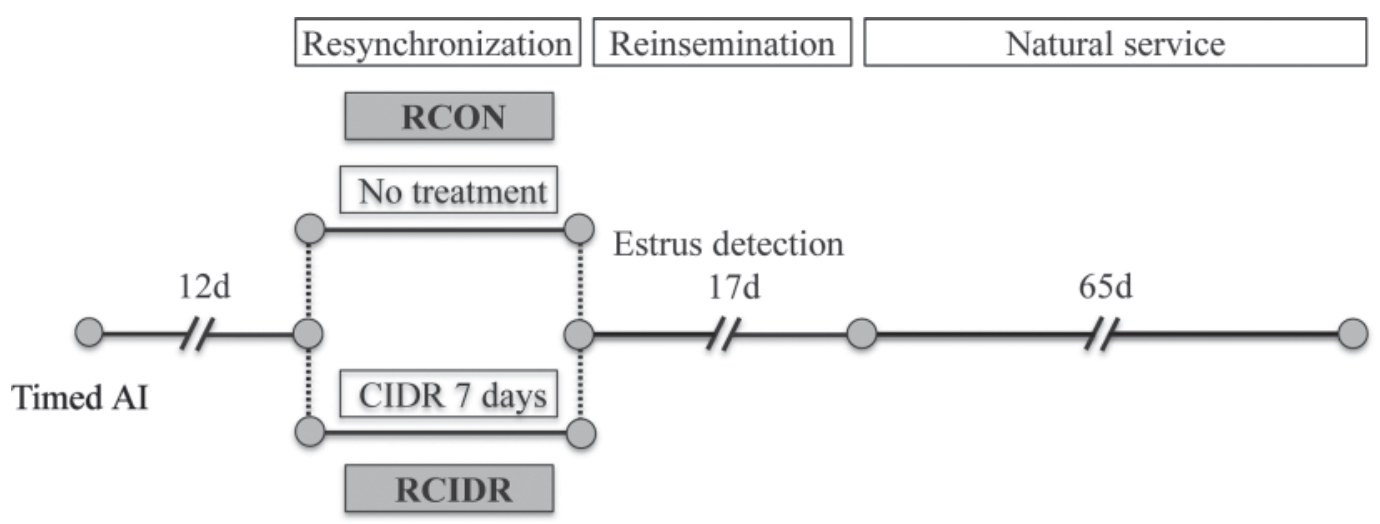

Study day

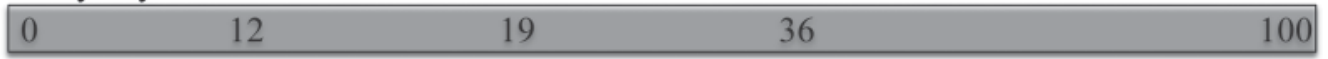

Figure 2. Diagram of activities during the resynchronization and natural service periods. CIDR $=$ controlled internal drug release containing $1.38 \mathrm{~g}$ of progesterone; RCIDR = treatment with CIDR; RCON = no treatment with CIDR (i.e., control). Cows in both treatments were observed once daily for signs of estrus between d 19 and 35, with reinsemination performed on the same morning that estrus was detected. On d 36 , bulls were placed with the cows for the remainder of the study.

Cattle Insert; Pfizer Animal Health Inc.) received an intravaginal insert from d 12 to 19 after the timed AI (RCIDR). Cows had their tailheads painted on d 18 and they were observed once daily, after the morning milking, for signs of estrus between d 19 and 35. Cows in estrus were inseminated in the same morning. Tail paint was re-applied as needed during the resynchronization period (d 19 to 35). Therefore, the 4 treatments were Presynch-RCON ( $=319)$, Presynch-RCIDR (n $=315)$, G6G-RCON (n = 319), and G6G-RCIDR (n $=310)$.

On d 36, Holstein and Jersey bulls were placed with all cows for additional $65 \mathrm{~d}$ of natural service to complete the 100-d breeding season. Bulls between 18 and 36 mo of age were used at a ratio of 1 bull for every 20 nonpregnant cows at the beginning of the natural service period.

\section{Blood Samples, Progesterone Analysis, and Characterization of Ovarian Status}

On $\mathrm{d}-8$, concurrent with the first $\mathrm{GnRH}$ of the timed AI protocol, blood was sampled by puncture of the coccygeal vein or artery into evacuated tubes containing $\mathrm{K}_{2}$ EDTA (Becton Dickinson and Co., Franklin Lakes, NJ). Samples were immediately placed on ice and transported to the laboratory within $6 \mathrm{~h}$ of collection. Tubes were centrifuged at $2,000 \times g$ for $15 \mathrm{~min}$ for plasma separation. Plasma samples were frozen at $-30^{\circ} \mathrm{C}$ and later analyzed for their concentrations of progesterone by RIA using a commercial kit (Coat-aCount; Siemens Healthcare Diagnostics, Los Angeles, CA). Samples were analyzed in 4 assays and the sensi- tivity of the assays calculated at 2 standard deviations below the mean counts per minute at maximum binding was $0.05 \mathrm{ng} / \mathrm{mL}$. The intra-assay $\mathrm{CV}$ was calculated for each duplicate and it averaged 5.9\%. Plasma samples of a cow $3 \mathrm{~d}$ after an injection of $\mathrm{PGF}_{2 \alpha}(0.4 \mathrm{ng} / \mathrm{mL})$ and on $\mathrm{d} 8$ of the estrous cycle $(4.0 \mathrm{ng} / \mathrm{mL})$ were repeated several times in all assays to calculate the inter-assay $\mathrm{CV}$, which were 20.4 and $5.5 \%$ for the samples containing 0.4 and $4.0 \mathrm{ng} / \mathrm{mL}$, respectively.

Ovarian status was categorized according to progesterone concentration as $\geq 1 \mathrm{ng} / \mathrm{mL}$ or $<1 \mathrm{ng} / \mathrm{mL}$. The cut-off of $1 \mathrm{ng} / \mathrm{mL}$ was chosen based on the receiveroperator characteristic curve to predict $\mathrm{P} / \mathrm{AI}$ on $\mathrm{d} 30$ after the timed AI with the highest combined sensitivity and specificity. At $1 \mathrm{ng} / \mathrm{mL}$, the sensitivity was $86.2 \%$, whereas the specificity was $31.3 \%$. Therefore, of all pregnant cows, $86.2 \%$ had progesterone on the day of the first $\mathrm{GnRH}$ of the timed $\mathrm{AI} \geq 1 \mathrm{ng} / \mathrm{mL}$. Twenty-seven of the initial 1,263 cows did not have a blood sample collected and they were excluded from the statistical analyses of the effect of presynchronization treatment on ovarian status on $\mathrm{d}-8$.

\section{BCS, DIM, and Milk Yield}

Cows were scored for body condition on a 1 to 5 scale ( 1 = emaciated, $5=$ obese; Ferguson et al., 1994) on d 0 (timed AI) and 30 (first pregnancy diagnosis). For statistical analyses, cows were categorized according to their body condition as $\mathrm{BCS} \leq 2.5, \mathrm{BCS}=2.75$ to 3.00 , or BCS $\geq 3.25$. Similarly, cows were categorized according to change in BCS from AI to pregnancy diagnosis as lost, no change, or gain. Cows were also categorized 
according to their DIM on d 0 as low $(<60$ DIM), medium (60 to $80 \mathrm{DIM})$, or high ( $>80$ DIM). Milk yield was measured once during the study when cows averaged 90 DIM.

\section{Pregnancy Diagnoses and Calculation of Reproductive Responses}

Pregnancy was diagnosed in all cows on d 30 via ultrasonography of the uterus and its contents, and was characterized by visualization of an embryo with heartbeat. Cows with a CL and fluid in the ipsilateral uterine horn, but without an embryo with heartbeat were considered as not pregnant. Cows diagnosed as pregnant on d 30 were reexamined by transrectal palpation 35 d later. Cows reinseminated after the first AI were examined by ultrasound between 30 and $43 \mathrm{~d}$ after reinsemination, and those pregnant were reexamined by transrectal palpation between 63 and $76 \mathrm{~d}$ after reinsemination. For the purpose of describing the dates when pregnancies were diagnosed, the first diagnosis will be called at d 30 and the second at d 65 after AI for the first timed AI and the resynchronized insemination. Pregnancies from natural service were diagnosed every $35 \mathrm{~d}$ after introduction of bulls and age of pregnancy was estimated based on size of the amniotic vesicle, either by ultrasound ( 28 to $35 \mathrm{~d}$ of gestation) or by transrectal palpation (36 to $63 \mathrm{~d}$ of gestation).

Pregnancy per AI was calculated as the number of pregnant cows on d 30 and 65 after an insemination divided by the total number of cows inseminated for the first and second AI. The reinsemination rate was calculated as the number of nonpregnant cows on $\mathrm{d} 30$ after the first AI that was reinseminated before introduction of the bulls. Pregnancy loss was calculated for the first and second AI as the number of cows that lost pregnancy between gestation d 30 and 65 divided by the number of pregnant cows on d 30 of each diagnosis. Pregnancy during natural service was calculated as the number of cows pregnant to bulls divided by the number of cows that did not become pregnant to AI. Finally, pregnancy at the end of the study was calculated as the number of pregnant cows on d 65 after a breeding (AI or natural service) divided by the total number of cows enrolled in the study. For survival analysis, cows that were sold, died, or remained as nonpregnant at the end of the 100-d breeding season were censored when the respective event occurred.

\section{Statistical Analyses}

All statistical models included the effects of presynchronization, resynchronization, and interaction between the 2 main effects, all of which were forced in the final models. Additional covariates (BCS on d 0, BCS change between d 0 and 30, breed of cow, DIM at first AI, farm, progesterone category on $\mathrm{d}-8$, parity, sire, and technician) were included when $P \leq 0.15$.

Binary data were analyzed by logistic regression using the LOGISTIC procedure of SAS version 9.2 (SAS/ STAT; SAS Institute Inc., Cary, NC). A stepwise backward elimination was used and covariates were removed based on the Wald statistics criterion when $P>0.10$. Adjusted odds ratio and 95\% confidence interval were calculated.

The interval to pregnancy was analyzed by the Cox proportional hazard model with the PHREG procedure of SAS. The hazard of pregnancy (adjusted hazard ratio, AHR) estimates the relative rate of pregnancy according to the explanatory variables used in the model. The time variable used in the model was the interval in days between $\mathrm{d} 0$ and pregnancy or censored (sold, dead, or remained open on d 100). A cow was considered pregnant based on the d 65 pregnancy diagnoses. A stepwise backward elimination was used to remove covariates when $P>0.10$. Proportionality was assessed by evaluating the Kaplan-Meier curves. The median and mean days to pregnancy were obtained from the LIFETEST procedure of SAS. Survival plots were generated with MedCalc version 9.2 (MedCalc Software bvba, Mariakerke, Belgium).

The concentration of progesterone on $\mathrm{d}-8$ and interval to reinsemination in cows rebred by AI were analyzed by ANOVA using the GLM procedure of SAS. Models included effects of presynchronization, resynchronization, interaction between presynchronization and resynchronization, BCS on d 0, breed of cow, farm, and parity.

Differences with $P \leq 0.05$ were considered significant and $0.05<P \leq 0.10$ were considered tendencies.

\section{RESULTS}

The BCS did not differ among treatments and it averaged $2.95 \pm 0.02$ and $2.85 \pm 0.02$ on $\mathrm{d} 0$ and 30 , respectively. Crossbred cows had greater $(P<0.01)$ BCS than Holstein and Jersey cows on d 0 (3.07 \pm 0.02 vs. $2.90 \pm 0.02$ vs. $2.91 \pm 0.03)$ and on $d 30$ (2.98 \pm 0.02 vs. $2.81 \pm 0.02$ vs. $2.78 \pm 0.03)$. The average milk yield did not differ among cows in the different treatments and averaged $27.0 \pm 0.6 \mathrm{~kg} / \mathrm{d}$, but Holsteins produced more $(P<0.01)$ milk than crossbreds, and the latter more $(P<0.01)$ than Jerseys $(31.1 \pm 0.7$ vs. $25.2 \pm 0.9$ vs. $21.8 \pm 0.6 \mathrm{~kg} / \mathrm{d})$. As expected, DIM at d 0 were similar for the 2 presynchronization treatments $(\mathrm{G} 6 \mathrm{G}=86.8 \pm 1.7$ DIM, with a minimum of 38 and a median of 72 DIM, and Presynch $=88.6 \pm 1.9$ DIM, with a minimum of 38 and a median of 72 DIM) and 
the 2 resynchronization treatments $(\mathrm{RCIDR}=87.9 \pm$ 1.8 DIM, with a minimum of 38 and a median of 72 $\mathrm{DIM}$, and $\mathrm{RCON}=87.5 \pm 1.8 \mathrm{DIM}$, with a minimum of 38 and a median of 73 DIM); however, they differed $(P<0.01)$ among breeds and Holsteins had fewer $(P$ $<0.001)$ DIM at first AI than the other breeds, but crossbreds and Jerseys did not differ (Holstein $=75.8$ \pm 1.4 vs. crossbreed $=91.4 \pm 2.0$ vs. Jersey $=95.9 \pm$ 3.7 DIM).

Because no interactions between presynchronization and resynchronization treatments were observed for display of estrus, $\mathrm{P} / \mathrm{AI}$, pregnancy loss, and pregnancy rate, data are presented separately for the effects of presynchronization and resynchronization treatments.

\section{Presynchronization Treatments}

The proportion of cows with progesterone $\geq 1 \mathrm{ng} /$ $\mathrm{mL}$ at the first $\mathrm{GnRH}$ injection of the timed AI was greater $(P<0.01)$ for G6G than Presynch (Table 1$)$. In spite of the improvement in presynchronization of the estrous cycle with G6G, P/AI on d 30 and 65 did not differ between the 2 presynchronization treatments, but pregnancy loss between d 30 and 65 after the first AI was greater $(P=0.05)$ for $\mathrm{G} 6 \mathrm{G}$ than Presynch. Nevertheless, an interaction existed between presynchronization treatment and ovarian status at the first GnRH injection of the timed AI protocol (Figure 3).
Among cows with progesterone $<1 \mathrm{ng} / \mathrm{mL}, \mathrm{G} 6 \mathrm{G}$ resulted in greater $(P<0.05) \mathrm{P} / \mathrm{AI}$ on $\mathrm{d} 30$ (41.5 vs. $26.3 \%)$ and 65 (35.3 vs. $24.6 \%$ ) after AI compared with Presynch. Conversely, among cows with progesterone $\geq 1 \mathrm{ng} / \mathrm{mL}, \mathrm{P} / \mathrm{AI}$ was greater $(P=0.02)$ for Presynch than G6G on d 65 (45.1 vs. 52.6\%) after AI. The concentration of progesterone for cows classified as $<1 \mathrm{ng} /$ $\mathrm{mL}$ at the first GnRH was greater $(P<0.01)$ for G6G than Presynch $(0.50 \pm 0.03$ vs. $0.28 \pm 0.03 \mathrm{ng} / \mathrm{mL})$, but for those classified as $\geq 1 \mathrm{ng} / \mathrm{mL}$, it did not differ between treatments and averaged $3.15 \pm 0.08 \mathrm{ng} / \mathrm{mL}$. Presynchronization treatment did not affect fertility responses during the periods of reinsemination and natural service, which resulted in similar proportions of cows pregnant at the end of the study. In fact, the median days to pregnancy were the same for G6G and Presynch because of the similar pregnancy rate (AHR $=0.96 ; 95 \% \mathrm{CI}=0.85$ to 1.08 ; Table 2 ).

\section{Resynchronization Treatments}

The proportions of cows with progesterone $\geq 1 \mathrm{ng} /$ $\mathrm{mL}$ and detected in estrus at timed AI were, as expected, similar between RCON and RCIDR groups (Table 3). The use of CIDR between d 12 and 19 after timed AI did not influence $\mathrm{P} / \mathrm{AI}$ and pregnancy loss after the first AI. Although RCIDR resulted in a similar proportion of nonpregnant cows reinseminated in

Table 1. Effect of presynchronization treatments on reproductive responses of grazing dairy cows

\begin{tabular}{|c|c|c|c|c|}
\hline \multirow[b]{2}{*}{ Item } & \multicolumn{2}{|c|}{ Presynchronization treatment ${ }^{1}[\%$ (no./no.)] } & \multirow{2}{*}{$\begin{array}{c}\mathrm{AOR}^{2} \\
(95 \% \mathrm{CI})\end{array}$} & \multirow[b]{2}{*}{$P$-value } \\
\hline & G6G & Presynch & & \\
\hline Detected in estrus & $34.5(217 / 629)$ & $36.1(229 / 634)$ & $1.02(0.80-1.30)$ & 0.84 \\
\hline Pregnant, d 30 & $49.9(312 / 625)$ & $49.1(310 / 632)$ & $1.10(0.86-1.36)$ & 0.60 \\
\hline Pregnant, d 65 & $43.3(269 / 622)$ & $45.1(285 / 632)$ & $1.10(0.87-1.38)$ & 0.62 \\
\hline \multicolumn{5}{|l|}{ Reinsemination in estrus } \\
\hline Reinseminated $^{5}$ & $68.7(215 / 313)$ & $70.5(227 / 322)$ & $0.92(0.65-1.31)$ & 0.66 \\
\hline Day of AI (LSM \pm SEM) & $24.1 \pm 0.5$ & $24.0 \pm 0.5$ & - & 0.75 \\
\hline Pregnant, d 30 & $48.6(104 / 214)$ & $53.2(117 / 220)$ & $1.19(0.80-1.76)$ & 0.39 \\
\hline Pregnant, d 65 & $45.8(98 / 214)$ & $49.6(109 / 220)$ & $1.16(0.79-1.72)$ & 0.44 \\
\hline Pregnancy loss ${ }^{6}$ & $5.8(6 / 104)$ & $6.8(8 / 117)$ & $1.18(0.37-3.76)$ & 0.78 \\
\hline Pregnant from natural service ${ }^{7}$ & $58.3(147 / 252)$ & $51.5(122 / 237)$ & $0.87(0.59-1.28)$ & 0.48 \\
\hline Pregnant at end of the study ${ }^{8}$ & $83.2(520 / 625)$ & $81.8(517 / 632)$ & $0.90(0.66-1.24)$ & 0.54 \\
\hline
\end{tabular}

${ }^{1}$ Presynch $=2$ injections of $\mathrm{PGF}_{2 \alpha}$, given $14 \mathrm{~d}$ apart and starting the timed AI protocol $11 \mathrm{~d}$ later; G6G $=\mathrm{PGF}_{2 \alpha}$ injection, followed $3 \mathrm{~d}$ later by GnRH injection and starting the timed AI protocol $6 \mathrm{~d}$ later.

${ }^{2}$ Adjusted odds ratio; G6G is the reference for comparison.

${ }^{3}$ Blood was not sampled from 12 G6G and 15 Presynch cows.

${ }^{4}$ The number of pregnant cows on d 30 that were not pregnant on d 65 divided by the number of pregnant cows on $\mathrm{d} 30$. Three G6G cows left the study before pregnancy reconfirmation on d 65 after AI.

${ }^{5}$ The proportion of nonpregnant cows reinseminated by AI after detection of estrus between d 19 and 35 after timed AI.

${ }^{6}$ The number of pregnant cows on d 30 that were not pregnant on d 65 divided by the number of pregnant cows on d 30 after reinsemination.

${ }^{7}$ The proportion of nonpregnant cows from AI that became pregnant from natural service.

${ }^{8}$ The proportion of cows pregnant at the end of the 100-d study. 

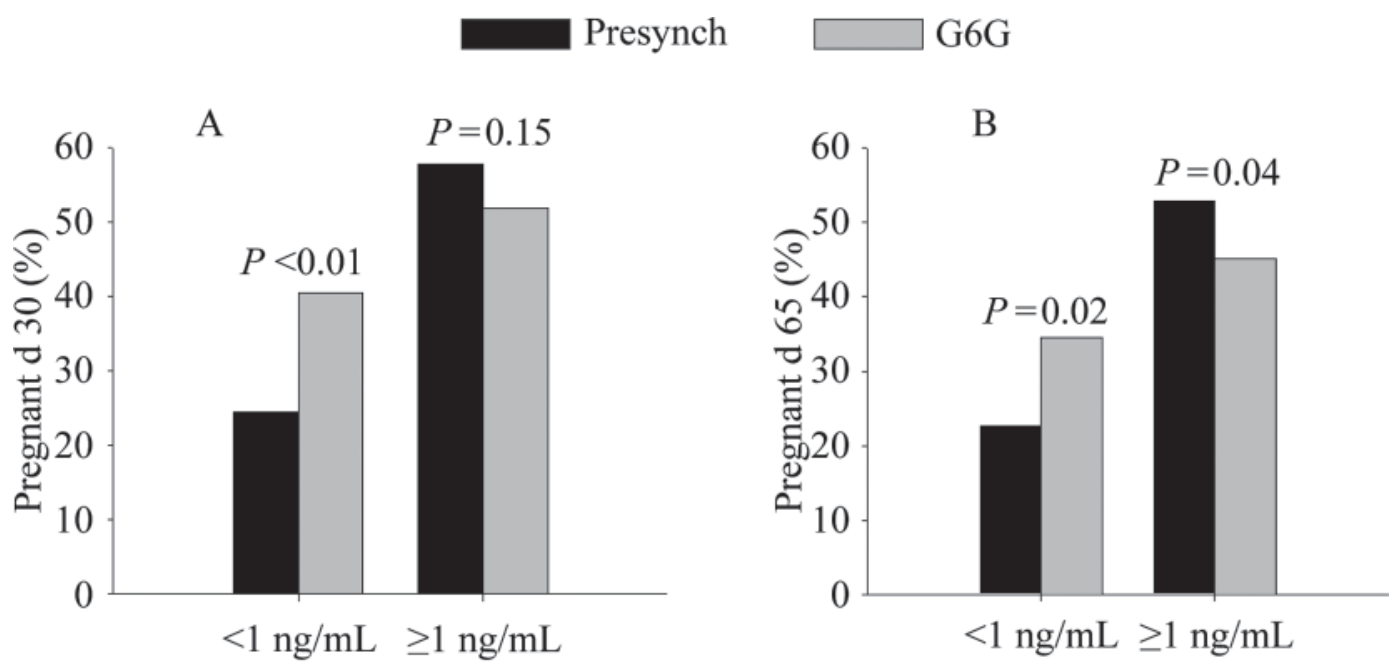

\section{Progesterone concentration at first GnRH of timed AI protocol}

Figure 3. Pregnancy on d 30 (A) and pregnancy on d 65 (B) after the first AI according to presynchronization treatment and category of progesterone concentration in plasma at the first GnRH injection of the timed AI protocol. For pregnancy on d 30, effect of presynchronization: $P=0.60$, progesterone category: $P<0.001$, and interaction between presynchronization and progesterone category: $P<0.001$. For pregnancy on d 65, effect of presynchronization: $P=0.62$, progesterone category: $P<0.001$, and interaction between presynchronization and progesterone category: $P<0.001$. Presynch $=2$ injections of $\mathrm{PGF}_{2 \alpha}$, given $14 \mathrm{~d}$ apart and starting the timed $\mathrm{AI}$ protocol $11 \mathrm{~d}$ later; $\mathrm{G} 6 \mathrm{G}=\mathrm{PGF} 2 \alpha$ injection, followed $3 \mathrm{~d}$ later by $\mathrm{GnRH}$ injection and starting the timed AI protocol $6 \mathrm{~d}$ later.

estrus compared with RCON, it altered the pattern of return to estrus. Cows receiving a CIDR had a smaller incidence of estrus on $\mathrm{d} 19$ and 20 (2.9 vs. $18.4 \%, P<$ $0.01)$, but greater on $\mathrm{d} 21$ to 24 (62.6 vs. $50.0 \%, P<$
0.01) than RCON cows, which resulted in a delay of 1.1 $\mathrm{d}$ in the mean interval to reinsemination. After $\mathrm{d} 24$, the proportion of cows reinseminated in estrus did not differ $(P=0.55)$ between RCON and RCIDR groups

Table 2. Cox's proportional hazard model for daily pregnancy rate of grazing dairy cows

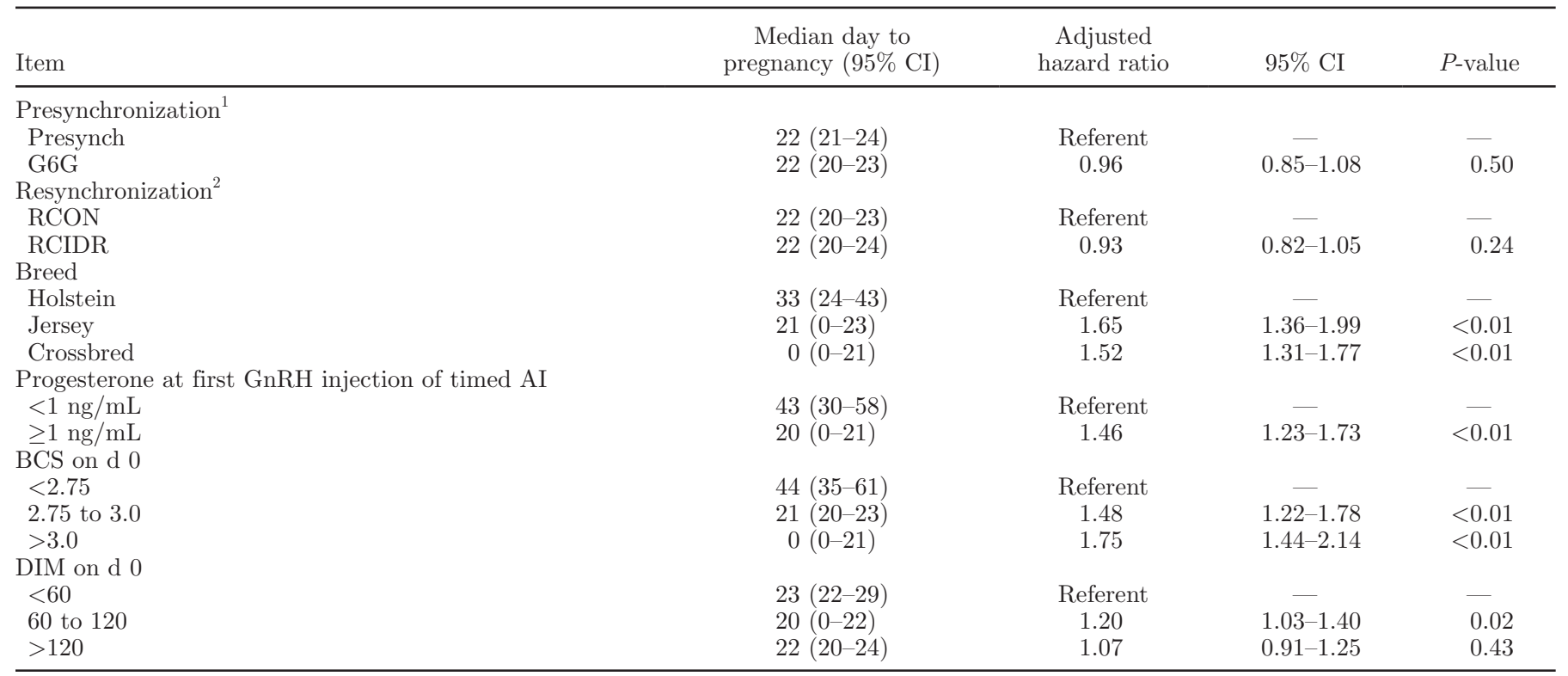

${ }^{1}$ Presynch $=2$ injections of $\mathrm{PGF}_{2 \alpha}$, given $14 \mathrm{~d}$ apart and starting the timed $\mathrm{AI}$ protocol $11 \mathrm{~d}$ later; G6G $=\mathrm{PGF}{ }_{2 \alpha}$ injection, followed $3 \mathrm{~d}$ later by GnRH injection and starting the timed AI protocol $6 \mathrm{~d}$ later.

${ }^{2}$ All cows were observed daily for signs of estrus from d 19 to $35 . \mathrm{RCON}=$ cows received no further treatment; RCIDR $=$ cows received a controlled internal drug release containing progesterone between d 12 and 19. 
(34.9 vs. $31.4 \%$ ). The $\mathrm{P} / \mathrm{AI}$ during the reinsemination period evaluated on d 30 and 65 after AI did not differ between RCIDR and RCON groups but, for cows reinseminated between $\mathrm{d} 21$ and 24 , it was less $(P=0.01)$ for RCIDR than RCON cows (39.7 vs. $58.1 \%$ ). A tendency $(P=0.08)$ for lower fertility in RCIDR compared with RCON cows was observed during natural service. Collectively, these differences resulted in a smaller $(P=$ 0.04) proportion of RCIDR than RCON cows pregnant at the end of the study (Table 3). Although the rate of pregnancy evaluated by the Cox model did not differ between RCON and RCIDR for all cows (Table 2), the same was not the case when only cows eligible for reinsemination were considered. When data were analyzed only with cows that did not become pregnant from the first AI and were eligible to be reinseminated during the resynchronization period (after d 19), then those in the RCIDR group had a slower rate of pregnancy (AHR $=0.81 ; 95 \% \mathrm{CI}=0.68$ to 0.97$)$ than $\mathrm{RCON}$ cows. In fact, for those cows, the median days to pregnancy were $64(95 \% \mathrm{CI}=57$ to 71$)$ and $54(95 \% \mathrm{CI}=46$ to 64$)$.

\section{Effects of Breed}

Holstein cows had, in general, poorer reproductive performance than Jersey and crossbred cows (Table 4). The proportions of Holstein cows with progesterone $\geq 1$ $\mathrm{ng} / \mathrm{mL}$ on $\mathrm{d}-8$ or in estrus at timed $\mathrm{AI}$, and the risk to become pregnant after the first AI were all less $(P<$ $0.01)$ than those of Jersey and crossbred cows. Similar responses were observed after the first AI. Holstein cows were less likely $(P<0.01)$ to be detected in estrus and reinseminated and had smaller $\mathrm{P} / \mathrm{AI}$ on $\mathrm{d} 30$ and 65 after the resynchronized AI compared with crossbred cows. During the natural service period, Holsteins were also less likely $(P<0.01)$ to become pregnant compared with Jerseys or crossbreds. Altogether, these differences resulted in a slower $(P<0.01)$ rate of pregnancy (Table 2; Figure 4A) and a smaller proportion of cows pregnant at the end of the study for Holsteins compared with Jerseys or crossbreds.

\section{Ovarian Status at the First GnRH Injection on Day -8}

Cows initiating the timed AI protocol with progesterone $\geq 1 \mathrm{ng} / \mathrm{mL}$ had greater $(P<0.01) \mathrm{P} / \mathrm{AI}$ at first AI (54.7 vs. $31.1 \%)$ and were more likely $(P=0.01)$ to be reinseminated in estrus than cows with progesterone $<1 \mathrm{ng} / \mathrm{mL}$ (75.7 vs. $59.2 \%$ ). The $\mathrm{P} / \mathrm{AI}$ during reinsemination, however, was not influenced by ovarian status on $\mathrm{d}-8$, and it averaged $46.3 \%$. Despite lack of statistical effect $(P=0.11)$ on the proportion of cows pregnant to natural service (progesterone $\geq 1 \mathrm{ng} /$ $\mathrm{mL}=59.7 \%$ vs. progesterone $<1 \mathrm{ng} / \mathrm{mL}=45.0 \%)$, those with progesterone $\geq 1 \mathrm{ng} / \mathrm{mL}$ had greater $(P<$ 0.01) pregnancy rate (Table 2; Figure $4 \mathrm{~B}$ ), resulting in

Table 3. Effect of resynchronization treatment on reproductive responses of grazing dairy cows

\begin{tabular}{|c|c|c|c|c|}
\hline Item & \multicolumn{2}{|c|}{ Resynchronization treatment $^{1}[\%$ (no./no.)] } & $\begin{array}{c}\mathrm{AOR}^{2} \\
(95 \% \mathrm{CI})\end{array}$ & $P$-value \\
\hline Progesterone $\geq 1 \mathrm{ng} / \mathrm{mL}$ on $\mathrm{d}-8^{3}$ & $78.0(490 / 628)$ & $78.3(476 / 608)$ & $0.96(0.72-1.28)$ & 0.77 \\
\hline \multicolumn{5}{|l|}{ Timed AI } \\
\hline Detected in estrus & $36.5(233 / 638)$ & $34.1(213 / 625)$ & $0.89(0.70-1.13)$ & 0.32 \\
\hline Pregnant, d 30 & $48.6(308 / 634)$ & $50.4(314 / 623)$ & $1.10(0.86-1.36)$ & 0.50 \\
\hline Pregnant, d 65 & $43.1(273 / 633)$ & $45.3(281 / 621)$ & $1.09(0.87-1.38)$ & 0.44 \\
\hline Reinseminated $^{5}$ & $69.3(226 / 326)$ & $69.9(216 / 309)$ & $0.99(0.70-1.41)$ & 0.97 \\
\hline Day of AI (LSM \pm SEM) & $23.5 \pm 0.5$ & $24.6 \pm 0.5$ & - & 0.04 \\
\hline Pregnant, d 30 & $54.3(121 / 223)$ & $47.4(100 / 211)$ & $0.78(0.53-1.14)$ & 0.20 \\
\hline Pregnant, d 65 & $51.6(115 / 223)$ & $43.6(92 / 211)$ & $0.74(0.51-1.09)$ & 0.13 \\
\hline Pregnancy loss ${ }^{6}$ & $5.0(6 / 121)$ & $8.0(8 / 100)$ & $1.92(0.61-6.09)$ & 0.27 \\
\hline Pregnant from natural service ${ }^{7}$ & $59.1(143 / 242)$ & $51.0(126 / 247)$ & $0.71(0.48-1.04)$ & 0.08 \\
\hline Pregnant at end of the study ${ }^{8}$ & $84.4(535 / 634)$ & $80.6(502 / 623)$ & $0.73(0.53-0.99)$ & 0.04 \\
\hline
\end{tabular}

${ }^{1}$ All cows were observed daily for signs of estrus from d 19 to 35. RCON $=$ cows received no further treatment; RCIDR $=$ cows received a controlled internal drug release containing progesterone between d 12 and 19.

${ }^{2}$ Adjusted odds ratio; RCON is the reference for comparison.

${ }^{3}$ Blood was not sampled from 10 RCON and 17 RCIDR cows.

${ }^{4}$ The number of pregnant cows on $\mathrm{d} 30$ that were not pregnant on $\mathrm{d} 65$ divided by the number of pregnant cows on $\mathrm{d} 30$. One RCON and 2 RCIDR cows left the study before pregnancy reconfirmation on d 65 after AI.

${ }^{5}$ Proportion of nonpregnant cows reinseminated by AI after detection of estrus between d 19 and 35 .

${ }^{6}$ The number of pregnant cows on d 30 that were not pregnant on d 65 divided by the number of pregnant cows on d 30 after reinsemination.

${ }^{7}$ The proportion of nonpregnant cows from AI that became pregnant from natural service.

${ }^{8}$ The proportion of cows pregnant at the end of the 100-d study. 
Table 4. Effect of breed on reproductive responses of grazing dairy cows

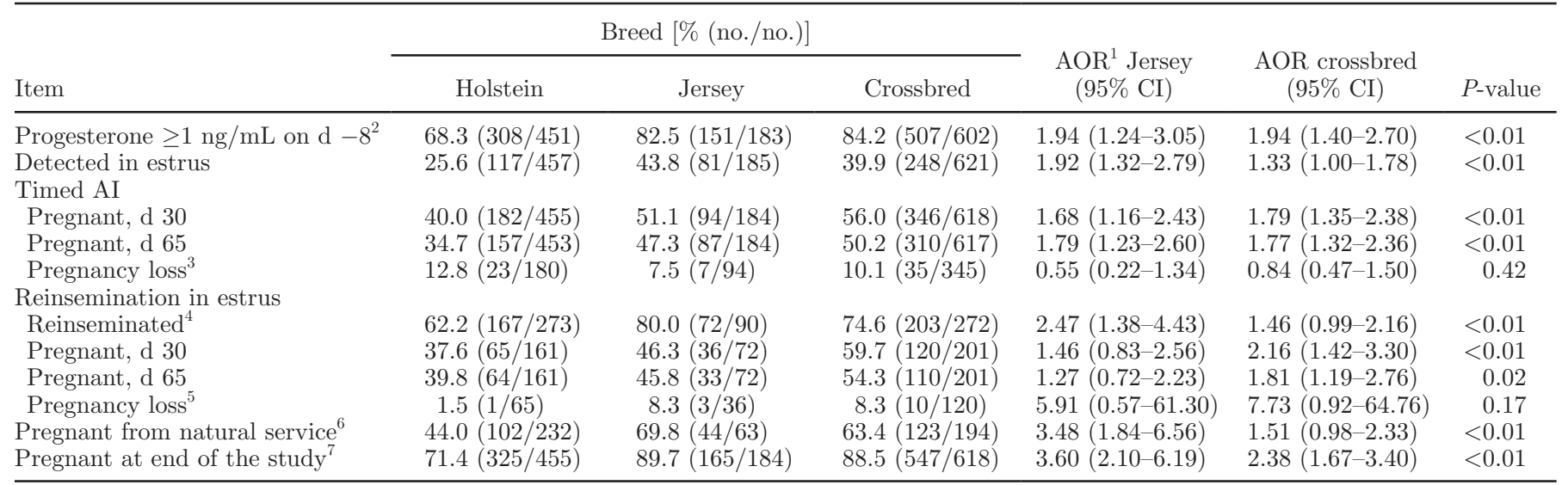

${ }^{1}$ Adjusted odds ratio; Holstein is the reference for comparison.

${ }^{2}$ Blood was not sampled from 6 Holstein, 2 Jersey, and 19 crossbred cows.

${ }^{3}$ The number of pregnant cows on d 30 that were not pregnant on d 65 divided by the number of pregnant cows on $\mathrm{d} 30$. Two Holstein and one crossbred cow left the study before pregnancy reconfirmation on d 65 after AI.

${ }^{4}$ The proportion of nonpregnant cows reinseminated by AI after detection of estrus between d 19 and 35.

${ }^{5}$ The number of pregnant cows on d 30 that were not pregnant on d 65 divided by the number of pregnant cows on d 30 after reinsemination.

${ }^{6}$ The proportion of nonpregnant cows from AI that became pregnant from natural service.

${ }^{7}$ The proportion of cows pregnant at the end of the 100-d study.

a greater $(P<0.01)$ proportion of them pregnant at the end of the study ( 86.1 vs. $69.9 \%)$.

\section{BCS and DIM at First AI}

Cows with BCS $<2.75$ were less likely $(P<0.01)$ to have a concentration of progesterone $\geq 1 \mathrm{ng} / \mathrm{mL}$ on $\mathrm{d}$ -8 than those with BCS from 2.75 to 3.00 and BCS $>3.00(59.8,81.7$, and $83.7 \%$, respectively). Furthermore, cows with BCS $<2.75$ had less $(P<0.01)$ expression of estrus at timed AI (20.3 vs. 37.0 vs. $47.0 \%)$ and $\mathrm{P} / \mathrm{AI}$ after timed AI (34.3 vs. 51.3 vs. $55.9 \%)$. Also, they were less likely $(P<0.01)$ to be reinseminated after the first AI (55.0 vs. 74.0 vs. $80.2 \%$ ). Despite lack of statistical effect $(P=0.24)$ on $\mathrm{P} / \mathrm{AI}$ during reinsemination ( 41.3 vs. 44.4 vs. $52.2 \%)$, a smaller $(P=0.01)$ proportion of cows with BCS $<2.75$ became pregnant with natural service (44.5 vs. 60.1 vs. $57.1 \%$ ). Collectively, these differences resulted in a slower pregnancy rate and extended interval to pregnancy for cows with BCS $<2.75$ (Table 2).

Cows classified as low DIM at timed AI were less likely $(P=0.02)$ to have progesterone $\geq 1 \mathrm{ng} / \mathrm{mL}$ on $\mathrm{d}$ -8 (71.7 vs. 80.4 vs. $82.2 \%)$, and tended $(P=0.09)$ to have lower $\mathrm{P} / \mathrm{AI}$ at timed AI (46.7 vs. 53.8 vs. $47.9 \%$ ) than those classified as medium and high, respectively. Proportions of reinseminated cows $(65.5$ vs. 66.8 vs. $74.7 \%$ ) and $\mathrm{P} / \mathrm{AI}$ after reinsemination (44.8 vs. 45.3 vs. $48.6 \%)$ were not affected $(P>0.10)$ by DIM, but cows classified as low DIM were reinseminated later $(P$
$<0.01)$ than medium- and high-DIM cows (25.0 vs. 23.3 vs. 23.3 d after AI), respectively. Pregnancy from natural service did not differ $(P=0.21)$ among the 3 categories of DIM (48.3 vs. 62.3 vs. $55.7 \%$ ). In general, cows classified as medium DIM at the first AI had the best pregnancy rate (Table 2$)$, and a greater $(P=0.04)$ proportion of them were pregnant by $100 \mathrm{~d}$ of breeding (77.5 vs. 86.5 vs. $83.4 \%$ ).

\section{DISCUSSION}

This study evaluated strategies to optimize pregnancy at the first and resynchronized AI in grazing dairy cows under a defined breeding period. Timed AI was used to ensure that all cows would be inseminated on the first day of the breeding season and also had an additional opportunity of AI on return to estrus before being exposed to natural service. Overall, $49.5 \%$ of the cows became pregnant to the first AI, but because of subsequent pregnancy loss, $44 \%$ were pregnant on d 65 of the study. Upon resynchronization, $67.1 \%$ of the cows became pregnant from insemination. These cows produce calves sired by AI, therefore of higher genetic and economic value than those sired by natural service (McDougall and Compton, 2006).

Presynch is commonly used to improve fertility of cyclic cows subjected to timed AI programs, whereas G6G was expected to target anovular cows. The former is commonly used in confinement dairy farms in the United States and has been shown to improve P/AI of 
A

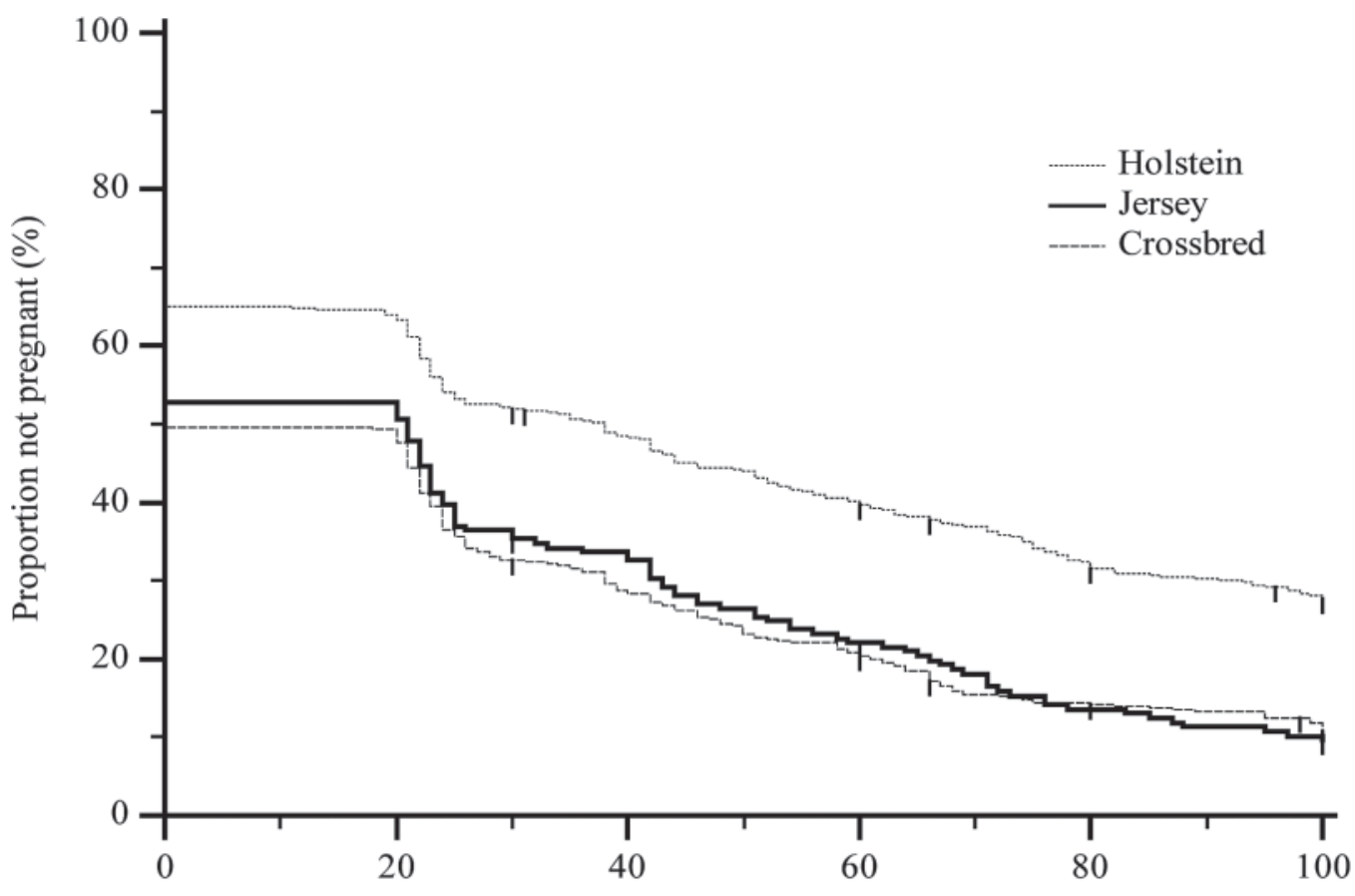

B

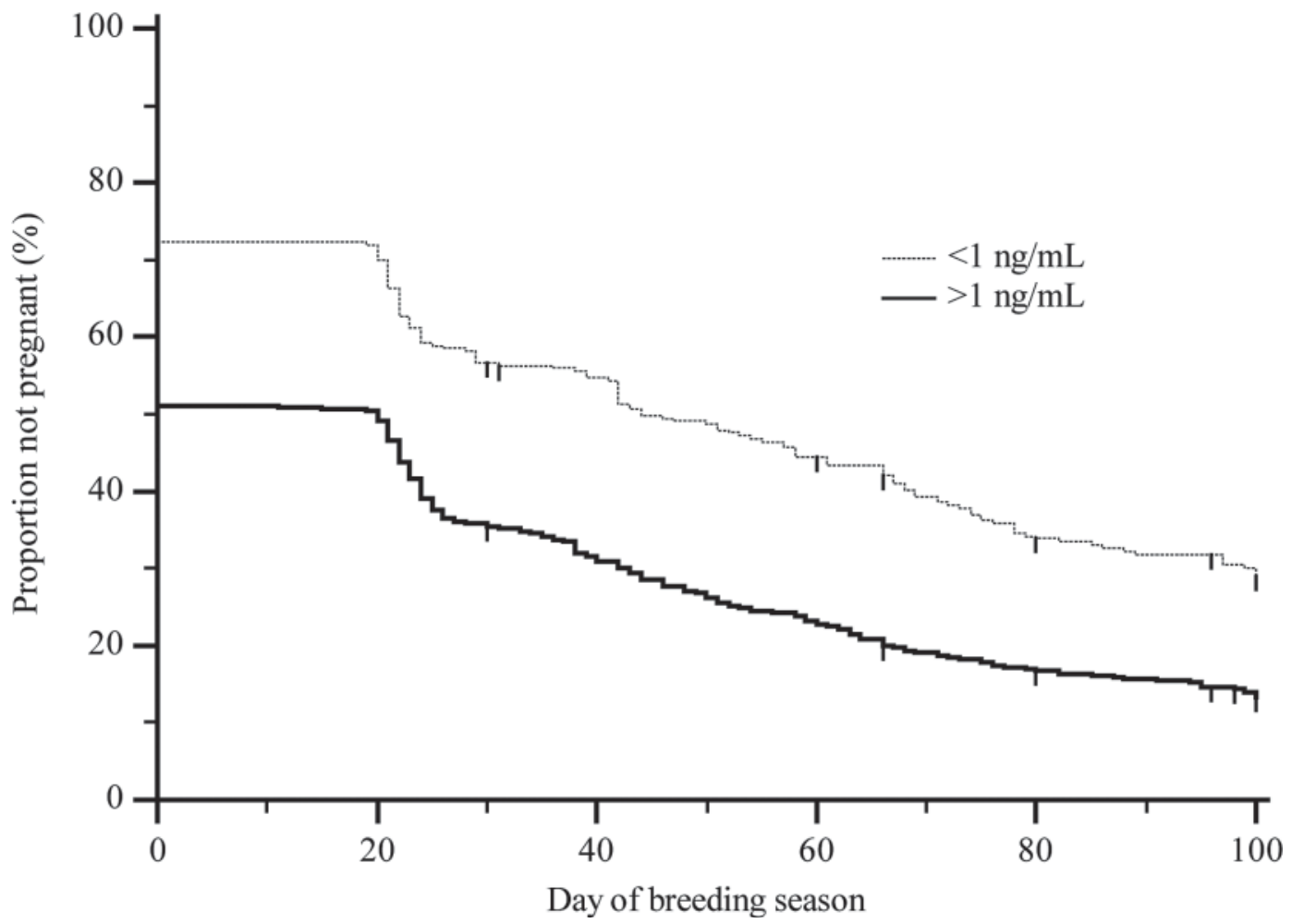

Figure 4. Survival curves for interval to pregnancy according to breed (panel A) and progesterone category at the first GnRH injection of the timed AI protocol (panel B). 
cyclic cows (Moreira et al., 2001; Galvão et al., 2007a); however, the high prevalence of noncycling cows in seasonally calving dairy herds, 13 to $48 \%$ (Rhodes et al., 2003), might limit its efficacy. On the other hand, the incorporation of $\mathrm{GnRH}$ treatment, as in the G6G, was expected to induce cyclicity and benefit anovular cows. Gonadotropin-releasing hormone is capable of inducing ovulation in $88 \%$ of the anovular cows (Gümen et al., 2003), and G6G was highly effective in improving the responses to the hormonal treatments during the Ovsynch protocol (Bello et al., 2006). In fact, G6G resulted in a greater proportion of cows with progesterone $\geq 1 \mathrm{ng} / \mathrm{mL}$ at the beginning of the timed $\mathrm{AI}$ protocol. Initiating the timed AI in early diestrus was expected to improve fertility of dairy cows (Bisinotto et al., 2010). Nevertheless, the method of presynchronization did not influence $\mathrm{P} / \mathrm{AI}$, although cows receiving G6G had greater pregnancy loss between 30 and $65 \mathrm{~d}$ of gestation after the first AI. The difference in pregnancy loss might suggest a benefit of the 2 sequential $\mathrm{PGF}_{2 \alpha}$ treatments on the ability of cows to maintain pregnancy, although it had a minor effect on the reproductive performance throughout the entire study. The sequential injections of $\mathrm{PGF}_{2 \alpha}$ in Presynch increase the opportunities for luteolysis and estrus. Studies have suggested a positive effect of $\mathrm{PGF}_{2 \alpha}$ on reproduction of dairy cows, presumably by improving uterine health (Kasimanickam et al., 2005; Galvão et al., 2009), although the effect of $\mathrm{PGF}_{2 \alpha}$ on uterine health of dairy cows has not been consistent (Dubuc et al., 2011).

It is interesting to note, however, that for cows with progesterone $<1 \mathrm{ng} / \mathrm{mL}$ at the initiation of the timed AI protocol, G6G resulted in greater P/AI than Presynch, but the opposite was observed for those with progesterone $\geq 1 \mathrm{ng} / \mathrm{mL}$. Considering the high efficiency of Presynch to synchronize the estrous cycle of cyclic cows, it is very likely that those with progesterone $<1$ $\mathrm{ng} / \mathrm{mL}$ were all anovular. On the other hand, a portion of the G6G cows with progesterone $<1 \mathrm{ng} / \mathrm{mL}$ was potentially cyclic not in diestrus, with a CL in development because of delayed ovulation. In fact, the progesterone concentration in this group of cows was greater for G6G than Presynch. It is possible that for cyclic cows, the Presynch is either a more efficacious method than G6G to presynchronize the estrous cycle or that the 2 sequential $\mathrm{PGF}_{2 \alpha}$ treatments benefit $\mathrm{P} /$ AI (Galvão et al., 2009) by influencing uterine health. On the other hand, the GnRH injection of G6G would result in high ovulation and formation of new CL, as has been demonstrated in anovular cows under confinement (Gümen et al., 2003; Galvão et al., 2007a). These cows would develop the ovulatory follicle under greater concentrations of progesterone than anovular cows in Presynch, which is important to improve $\mathrm{P} / \mathrm{AI}$
(Bisinotto et al., 2010). Others have evaluated variations in presynchronization methods combining $\mathrm{GnRH}$ with $\mathrm{PGF}_{2 \alpha}$ compared with the Presynch (Galvão et al., 2007a). Adding an injection of GnRH to the presynchronization program did not benefit $\mathrm{P} / \mathrm{AI}$ in lactating dairy cows under confinement housing. When compared with no presynchronization, a combination of $\mathrm{PGF}_{2 \alpha}$ and $\mathrm{GnRH}$ did not increase $\mathrm{P} / \mathrm{AI}$ in lactating dairy cows (Peters and Pursley, 2002). Recent work by our group demonstrated that presynchronization of the estrous cycle benefited P/AI of grazing cows compared with no presynchronization and supplementation of progesterone during the timed AI (Ribeiro et al., 2010). Collectively, these results indicate that the Presynch and the G6G methods of presynchronization resulted in similar fertility following the timed AI program in grazing dairy cows; although Presynch was superior in cyclic cows, G6G constitutes an alternative to shorten the length of the timed AI program (17 vs. $33 \mathrm{~d}$ ), particularly in herds with high prevalence of anovular cows.

Reinsemination of nonpregnant cows is another important component of a program to optimize reproductive efficiency in grazing dairy farms. The programs selected had a predefined period of detection of estrus to minimize labor with resynchronization between d 19 and 35. The use of the CIDR was expected to improve the synchrony of return to estrus, and d 19 was selected for its removal to minimize the risk of depressing fertility of the resynchronized AI (Galvão et al., 2007b). As observed by others (El-Zarkouny and Stevenson, 2004; Chebel et al., 2006; Galvão et al., 2007b), the CIDR altered the pattern of return to estrus. It concentrated estruses on d 2 to $4 \mathrm{~d}$ after insert removal, but it did not improve the proportion of nonpregnant cows reinseminated. In some cases, use of CIDR to resynchronize estrus resulted in improved reinsemination of nonpregnant cows (Chenault et al., 2003), but this response has not been consistent. In fact, as observed in the current experiment, most studies have shown no benefit of the use of the CIDR to improve insemination of nonpregnant cows (Chebel et al., 2006; Galvão et al., 2007b).

Despite similar proportions of nonpregnant cows reinseminated, RCIDR cows detected in estrus between d 21 and 24 had decreased fertility compared with RCON cows in the same period. Chenault et al. (2003) also observed a detrimental effect of the CIDR during resynchronization on $\mathrm{P} / \mathrm{AI}$, which the authors associated with vaginitis. Mucus score was not evaluated in the current study because several other authors were not able to associate the appearance of the vaginal mucus with fertility in dairy cows following the use of intravaginal inserts (Galvão et al., 2004; Chebel et al., 2006; Galvão et al., 2007b). By design, RCON cows that were 
in estrus before d 19 were not inseminated; however, in RCIDR, progesterone from the insert likely prevented estrous expression and forced them to display estrus after d 19. For cows not bearing a CL, the CIDR would maintain subluteal concentrations of progesterone, which extends the period of follicle dominance and exposes the oocyte to increased LH pulsatility. Extending dominance is often detrimental to subsequent fertility (Inskeep, 2004). These results do not support the use of CIDR to optimize reinsemination of nonpregnant cows in a grazing system as used in the current study.

Holsteins, Jerseys, and Holstein $\times$ Jersey crossbreds were enrolled in the study, and these genetic groups had distinct milk production and reproductive performance under the production system used. Holsteins received their first AI sooner postpartum than did crossbreds and Jerseys, and DIM at first AI influenced the fertility of dairy cows. This difference in DIM might have contributed to the decreased pregnancy rate of Holsteins compared with the other genetic groups, although we accounted for the differences in DIM among genetic groups by including it in all statistical models. Limited nutrition usually has more negative effects on fertility of animals that partition more nutrients toward milk than body reserves. Holstein cows had lower BCS than crossbreds at the beginning of the study, although it did not differ from that of Jerseys. However, Holsteins have greater requirements for maintenance and production because of larger body weight and increased production of milk. Therefore, when nutrient intake is limiting, cows of greater genetic potential for milk yield experience greater losses of BW and body condition (Macdonald et al., 2008), which can compromise reproduction (Santos et al., 2009). Other studies have also reported advantages in reproductive parameters of Jerseys and crossbreds compared with Holsteins, such as a shorter interval to first ovulation, fewer days open, greater estrous detection, and increased P/AI (Washburn et al., 2002; Freyer et al., 2008; Heins et al., 2008). In the current study, the estimated proportions of anovular cows, based on those with progesterone $<1$ $\mathrm{ng} / \mathrm{mL}$ from the Presynch treatment were 32.0, 11.6, and $12.6 \%$ for Holstein, Jersey, and crossbred cows, respectively. Delayed cyclicity has a depressive effect on fertility (Rhodes et al., 2003; Santos et al., 2009). The observed differences among the breeds might have been mediated by differences in nutrient balance in early lactation. Another possibility is a potential genetic difference among the groups, as Holsteins and Jerseys have suffered different changes in reproductive efficiency over time, and crossbred cows have the advantage of hybrid vigor and less inbreeding. Therefore, in a production system that limits nutrient intake, the combination of different nutrient needs for maintenance and production, BCS, cyclicity, and genetics for fertility might explain the worse reproductive efficiency of Holsteins compared with Jersey and crossbred cows.

\section{CONCLUSIONS}

Presynchronization with $\mathrm{PGF}_{2 \alpha} / \mathrm{GnRH}$, as in the G6G, increased the proportion of cows with progesterone $\geq 1 \mathrm{ng} / \mathrm{mL}$ at the beginning of the timed AI protocol compared with Presynch, but it did not influence $\mathrm{P} / \mathrm{AI}$ and increased risk of pregnancy loss after timed AI. At first AI, Presynch was generally more beneficial to cows starting the timed AI with progesterone $\geq 1 \mathrm{ng} /$ $\mathrm{mL}$, whereas $\mathrm{G} 6 \mathrm{G}$ was more beneficial to cows starting the timed AI with progesterone $<1 \mathrm{ng} / \mathrm{mL}$. Resynchronization with CIDR did not increase the rate of reinsemination of nonpregnant cows after the first AI, and resulted in a smaller proportion of cows pregnant at the end of the breeding season. Finally, matching the proper genetics and management to the production system is expected to optimize reproductive efficiency of the herd. The reproduction of crossbred and Jersey cows was generally superior to that of Holsteins. Finally, cows with a minimum BCS of 2.75 , starting the timed AI program with progesterone $\geq 1 \mathrm{ng} / \mathrm{mL}$, and those with at least 60 DIM were all important factors that benefited reproduction.

\section{ACKNOWLEDGMENTS}

The authors thank the owner and staff of Piedmont and Watson Dairies (Trenton, FL) for use of their cows and facilities. The assistance of Nilo Francisco, Pat Cilo Cilo, and Cliff Reindl of Alliance Dairies (Trenton, NJ) is greatly appreciated. Our appreciation is extended to Frederico Moreira of Pfizer Animal Health (Madison, NJ) for providing the Lutalyse and CIDR inserts.

\section{REFERENCES}

Bello, N. M., J. P. Steibel, and R. J. Pursley. 2006. Optimizing ovulation to first $\mathrm{GnRH}$ improved outcomes to each hormonal injection of Ovsynch in lactating dairy cows. J. Dairy Sci. 89:3413-3424.

Bisinotto, R. S., R. C. Chebel, and J. E. P. Santos. 2010. Follicular wave of the ovulatory follicle and not cyclic status influences fertility of dairy cows. J. Dairy Sci. 93:3578-3587.

Cerri, R. L., H. M. Rutigliano, R. C. Chebel, and J. E. P. Santos. 2009. Period of dominance of the ovulatory follicle influences embryo quality in lactating dairy cows. Reproduction 137:813-823.

Chebel, R. C., J. E. P. Santos, R. L. A. Cerri, H. M. Rutigliano, and R. G. S. Bruno. 2006. Reproduction in dairy cows following progesterone insert presynchronization and resynchronization protocols. J. Dairy Sci. 89:4205-4219.

Chenault, J. R., J. F. Boucher, K. J. Dame, J. A. Meyer, and S. L. Wood-Follis. 2003. Intravaginal progesterone insert to synchronize return to estrus of previously inseminated dairy cows. J. Dairy Sci. 86:2039-2049.

Dubuc, J., T. F. Duffield, K. E. Leslie, J. S. Walton, and S. J. LeBlanc. 2011. Randomized clinical trial of antibiotic and prostaglan- 
din treatments for uterine health and reproductive performance in dairy cows. J. Dairy Sci. 94:1325-1338.

El-Zarkouny, S. Z., and J. S. Stevenson. 2004. Resynchronizing estrus with progesterone or progesterone plus estrogen in cows of unknown pregnancy status. J. Dairy Sci. 87:3306-3321.

Ferguson, J. D., D. T. Galligan, and N. Thomsen. 1994. Principal descriptors of body condition score in Holstein cows. J. Dairy Sci. 77:2695-2703.

Freyer, G., S. König, B. Fischer, U. Bergfeld, and B. G. Cassell. 2008. Invited review: Crossbreeding in dairy cattle from a German perspective of the past and today. J. Dairy Sci. 91:3725-3743.

Galvão, K. N., M. Frajblat, S. B. Brittin, W. R. Butler, C. L. Guard, and R. O. Gilbert. 2009. Effect of prostaglandin $F_{2 \alpha}$ on subclinical endometritis and fertility in dairy cows. J. Dairy Sci. 92:49064913.

Galvão, K. N., M. F. Sá Filho, and J. E. P. Santos. 2007a. Reducing the interval from presynchronization to initiation of timed AI improves fertility in dairy cows. J. Dairy Sci. 90:4212-4218.

Galvão, K. N., J. E. P. Santos, R. L. Cerri, R. C. Chebel, H. M. Rutigliano, R. G. Bruno, and R. C. Bicalho. 2007b. Evaluation of methods of resynchronization for insemination in cows of unknown pregnancy status. J. Dairy Sci. 90:4240-4252.

Galvão, K. N., J. E. P. Santos, S. O. Juchem, R. L. A. Cerri, A. C. Coscioni, and M. Villaseñor. 2004. Effect of addition of a progesterone intravaginal insert to a timed insemination protocol using estradiol cypionate on ovulation rate, pregnancy rate, and late embryonic loss in lactating dairy cows. J. Anim. Sci. 82:3508-3517.

Gümen, A., J. N. Guenther, and M. C. Wiltbank. 2003. Follicular size and response to Ovsynch versus detection of estrus in anovular and ovular lactating dairy cows. J. Dairy Sci. 86:3184-3194.

Heins, B. J., L. B. Hansen, A. J. Seykora, D. G. Johnson, J. G. Linn, J. E. Romano, and A. R. Hazel. 2008. Crossbreds of Jersey $\times$ Holstein compared with pure Holsteins for production, fertility, and body and udder measurements during first lactation. J. Dairy Sci. 91:1270-1278.

Inskeep, E. K. 2004. Preovulatory, postovulatory, and postmaternal recognition effects of concentrations of progesterone on embryonic survival in the cow. J. Anim. Sci. 82(E-Suppl.):E24-E39.

Kasimanickam, R., T. F. Duffield, R. A. Foster, C. J. Gartley, K. E. Leslie, J. S. Walton, and W. H. Johnson. 2005. The effect of a single administration of cephapirin or cloprostenol on the reproductive performance of dairy cows with subclinical endometritis. Theriogenology 63:818-830.
Macdonald, K. A., G. A. Verkerk, B. S. Thorrold, J. E. Pryce, J. W. Penno, L. R. McNaughton, L. J. Burton, J. A. S. Lancaster, J. H. Williamson, and C. W. Holmes. 2008. A comparison of three strains of Holstein-Friesian grazed on pasture and managed under different feed allowances. J. Dairy Sci. 91:1693-1707.

McDougall, S. 2010. Comparison of diagnostic approaches, and a costbenefit analysis of different diagnostic approaches and treatments of anoestrous dairy cows. N. Z. Vet. J. 58:81-89.

McDougall, S., and C. W. R. Compton. 2006. Reproductive performance in the subsequent lactation of dairy cows previously treated for failure to be detected in oestrus. N. Z. Vet. J. 54:132-140.

Moreira, F., C. Orlandi, C. A. Risco, R. Mattos, F. Lopes, and W. W. Thatcher. 2001. Effects of presynchronization and bovine somatotropin on pregnancy rates to a timed artificial insemination protocol in lactating dairy cows. J. Dairy Sci. 84:1646-1659.

Peters, M. W., and J. R. Pursley. 2002. Fertility of lactating dairy cows treated with Ovsynch after presynchronization injections of $\mathrm{PGF}_{2 \alpha}$ and GnRH. J. Dairy Sci. 85:2403-2406.

Rhodes, F. M., S. McDougall, C. R. Burke, G. A. Verkerk, and K. L. Macmillan. 2003. Treatment of cows with an extended postpartum anestrous interval. J. Dairy Sci. 86:1876-1894.

Ribeiro, E. S., R. S. Bisinotto, M. Favoreto, L. T. Martins, R. L. A Cerri, F. T. Silvestre, L. F. Greco, W. W. Thatcher, and J. E. P. Santos. 2010. Pregnancy per AI (P/AI) of dairy cows following presynchronization and splitting the prostaglandin (PGF) injection in the 5d-Cosynch protocol. J. Dairy Sci. 93(E-Suppl. 1):393. (Abstr.)

Santos, J. E. P., C. D. Narciso, F. Rivera, W. W. Thatcher, and R. C. Chebel. 2010. Effect of reducing the period of follicle dominance in a timed AI protocol on reproduction of dairy cows. J. Dairy Sci. 93:2976-2988.

Santos, J. E. P., H. M. Rutigliano, and M. F. Sá Filho. 2009. Risk factors for resumption of postpartum cyclicity and embryonic survival in lactating dairy cows. Anim. Reprod. Sci. 110:207-221.

Vasconcelos, J. L. M., R. W. Silcox, G. J. M. Rosa, J. R. Pursley, and M. C. Wiltbank. 1999. Synchronization rate, size of the ovulatory follicle, and pregnancy rate after synchronization of ovulation beginning on different days of the estrous cycle in lactating dairy cows. Theriogenology 52:1067-1078.

Washburn, S. P., S. L. White, J. T. Green Jr., and G. A. Benson. 2002. Reproduction, mastitis and body condition of seasonally calved Holstein and Jersey cows in confinement or pasture systems. J. Dairy Sci. 85:105-111. 